\title{
Contrastive Analysis and its Implications for Bengali Learners of ESL
}

\section{Arjumand Ara}

Assistant Professor, University of Asia Pacific, Dhaka, Bangladesh

\section{OPEN ACCESS}

Manuscript ID:

EDU-2021-09033827

Volume: 9

Issue: 3

Month: June

Year: 2021

P-ISSN: 2320-2653

E-ISSN: 2582-1334

Received: 11.03.2021

Accepted: 28.04.2021

Published: 01.06.2021

Citation:

Ara, Arjumand.

"Contrastive Analysis and Its Implications for Bengali Learners of ESL." Shanlax International Journal of Education, vol. 9, no. 3, 2021, pp. 79-83.

DOI:

https://doi.org/10.34293/ education.v9i3.3827

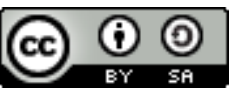

This work is licensed under a Creative Commons Attribution-ShareAlike 4.0 International License

\begin{abstract}
Contrastive Analysis, since its introduction as a potential predictor of the influence of the learners' first language on the second language and the resultant errors, has constantly been subject to criticism on both theoretical and empirical grounds. This once-popular approach of interpreting errors resulting from the interference from the native language met a gradual decline in acceptability as Behaviorism, the theory on which it was based, lost its credibility. Also, empirical findings pointed out its ineffectiveness as the predictor of errors. However, contrastive analysis projects have been carried out in different parts of the world to avoid errors in specific language areas, including pronunciation. This paper aims to shed light on the origin, evolution and significance of the theory, especially in designing instructional materials for the Bengali learners of English as a second language.
\end{abstract}

Keywords: Contrastive analysis, Interference of L1, Errors in SL, Native language, Target language

\section{Introduction}

Contrastive analysis (CA) is concerned with the influence of the native language $(\mathrm{NL})$ in second language acquisition. Contrastive analysis is carried out by comparing the first language (L1) of the learners and the target language (TL) to identify potential errors for the primary purpose of sorting out which areas of the TL should be focused on and which areas do not need to be focused on in the context of second language learning (Gass, et al., 2013). The contrastive analysis hypothesis $(\mathrm{CAH})$ was popularized by Lado with his publication of the book "Linguistics Across Cultures" (1957). Fries (1945) introduced the idea of CA earlier, assuming that errors will be produced by the areas of the target language which lack resemblance with the corresponding areas in the native language with the implication that teachers will be able to predict the learning difficulties to be experienced by the learners by contrasting the two languages. Although CA was extensively used in the 1960s and the early years of the 1970s, it gradually came to be criticized on several grounds, including theoretical and empirical. The validity of the hypothesis itself was questioned. However, its significance as the pioneering study on the influence of the L1 on the second language (L2) and its role in developing subsequent theories, especially error analysis and the inter-language theories, was recognized. This paper, thus, will discuss its origin, the criticisms received, and its role on second language acquisition (SLA) as the predictor of errors. Finally, it will consider whether it has any implications for the SLA classroom for Bengali learners. 


\section{Behaviorism and Contrastive Analysis Hypothesis (CAH)}

To explain the role of L1 in L2, the Contrastive Analysis Hypothesis (CAH), the concern of which was pedagogic, was put forward. In SLA, this theory assumes that the already established L1 habits of the learners will interfere with forming new habits in the L2. Lado (1957) based his ideas on the theoretical position of his time, i.e., behaviorism, the leading psychological school of thought. According to the propagators of this theory, all learning, including language learning, happens through imitation, practice, reinforcement and habit formation. Environment plays a major role because children learn their L1 by repeating what they hear in the surrounding environment. When their utterances approximate the input in the environment that they are exposed to, these efforts receive positive reinforcement and habits are thus formed (Skinner 1957).

In contrastive analysis, comparisons of the two languages were carried out in the belief that interference and the resulting learning difficulty could be predicted by identifying those areas of TL that were different from learners' L1. In this regard, Lado (1957) postulated that if teachers made a comparison of the foreign language with the native one of the learners, he/she would know about the real problems of the learners and in this way could provide for teaching them. According to Weinrick (1953) and Labov (1966), learners of a second language already have in their possession habits of using their native language. Skinner (1957) also put forward the idea that children's present learning will be influenced by their past learning. The knowledge of the native tongue, in the case of language learning, will ease the process. Some of these previously learned habits will help them to learn the rules of the new language, whereas some others will pose problems for them. When learners try to apply the rules and forms of their native language to the target language, 'transfer' occurs. The positive transfer will happen if some structures of both languages are similar.

On the other hand, negative transfer or interference will occur if some of the forms and grammatical structures in both languages are not similar. In syntax, learners are likely to draw upon the stylistic features of their native language unknowingly. They will make errors when the syntactical features of both languages vary.

Within the framework of $\mathrm{CAH}$, two positions were developed. First of all, the a priori (also known as strong or predictive) view posited that CA could make predictions about learning and hence the success of language teaching materials based on a comparison between two languages. Secondly, a posteriori (also known as weak or predictive) view emphasized that errors must be analyzed first. Based on this knowledge, an attempt could be made to account for that knowledge based on NL-TL difference.

\section{Criticism against $\mathrm{CAH}$}

$\mathrm{CAH}$ has been subjected to strong criticism since it emerged. The criticisms were first targeted to its theoretical underpinnings. Theoretically, behaviorism lost its appeal as it explained all learning in simple terms of imitation, repetition and habit formation and stressed no importance on the human mind as a construct. In the latter half of the 1950s, Chomsky made serious challenges against Behaviorism and structuralism, which ultimately led to the decline of the CA.

The strong form of the $\mathrm{CAH}$ has also been criticized on the ground that we cannot explain all errors made by L2 learners in terms of language transfer alone. Researchers (e.g., Gass, et al., 2013) found that the actual learners did not produce many errors that had been predicted. The role of interference was also considered as overemphasized and it was thought that learning L2 involves exclusively overcoming the effects of the NL (Tajareh, 2015). The subsequent development of the inter-language theory added to its weakness by enlisting various sources of errors, of which L1 interference was only one.

Different studies (e.g., the study by Duskova, 1984) have shown that language interference does not always indicate the types of errors learners will make. The research evidence gives rise to several issues. First of all, certain elements in a language are intrinsically difficult and learners may produce errors regardless of their native language. In this respect, 
we can say that in English, the prepositions are quite large in number and they are used so variedly that it is difficult to categorize them following any criteria. Secondly, CA does not account for the phenomenon of "avoidance,' i.e., learners avoiding the use of grammatical structures that they find difficult. Schachter (1974), in her study on the use of English relative clauses, found that the learners whose L1 did not have that category used them less than the students whose first languages had that category. The former made fewer mistakes than the latter as they avoided using relative clauses and used alternative categories.

The concept of difficulty was itself put into question. Gass, et al., (2013), for example, argued that Lado (1957), in his CA hypothesis, aimed to identify the areas of the target language that learners would find difficult. However, in practice, CA was utilized to predict errors assuming that the concepts of error and difficulty were inseparable. Gass, et al., (2013) further explained that the concept of difficulty is psycholinguistic, whereas errors are a natural outcome of language learning. Learners are likely to focus on aspects of the target language that they perceive as difficult, whereas they may give less focus on the areas which they perceive as not difficult and consequently make errors. In SLA, these types of mistakes are known as "careless mistakes" (Lennon, 2008). CA views learners as passive individuals influenced by language interference. As pointed out by Lennon (2008), learners are not mechanical beings.

Another important flaw of CA is that the errors learners make in the second language can sometimes be bi-directional. Zobl (1980) found that English learners of French-made errors use pronouns with the object (* le chien mange le). The French learners of English did not make such mistakes, although, in both these languages, pronouns are placed differently with the objects. Inter-language transfer is not the only reason why students make errors. Research has found that interlingual and intra-lingual factors combinedly produce errors. For instance, all English learners as a second language in the initial learning stage produce pre-verbal negation (e.g., 'no eat').

Again, several studies revealed that many errors in the learners' L2 could be explained better in terms of his/her developing knowledge of the structure of the TL. In the1970s, several error analysis studies classified L2 learners' errors and found that many could not be attributed to L1 influence (Richard, 1974). This led some researchers to reject traditional CA and claim that L2 learners did not rely on the L1 as a source of hypotheses about L2 (Dulay and Burt, 1976).

\section{Reappraisal of CAH}

Lennon (2008) explained that the CA model is weak in the prediction of errors produced at syntactical or lexical levels as learners may tend to use strategies like avoiding difficult structures or simplifying the subsystems of the TL. However, it works well for the prediction of phonological errors (Lennon 2008, Tajareh, 2015). Ashour's (2017) study made a contrastive analysis between English and Arabic pronunciation systems and found that these two languages have very different pronunciation systems, with the former being a stress-timed language while the latter is a syllabictimed language. This difference caused learners to face difficulties in distinguishing consonant sounds such as $/ \mathrm{p} /$ and $/ \mathrm{b} /$ and when they have to pronounce consonant clusters.

Anjarningsih and Saraayu (2015), in their study using the Contrastive Analysis Hypothesis, investigated the reasons for different kinds of pronunciation of English words by Japanese learners of English. Their study revealed the interference of the native language, including additional vowel sounds, syllabic changes, changed manners of vowel articulation, consonantal changes and elisions of consonants in different English words. Kissová (2020) investigated the use of the contrastive approach to increase the positive transfer and decrease the negative transfer of the first language in the L2 of young Slovak learners. This mixed-method research was carried out to assess the needs of the learners in learning English (L2) pronunciation.

\section{$\mathrm{CAH}$ and Implications for the Language Classroom}

Based on the discussion in the previous section, it can be said that CA still holds strong pedagogical implications, especially in the case of teaching 
pronunciation. Recent studies carried out by Barman (2009), Islam (2017) and Islam (2018) pointed out the significance of CA in the second language classroom of Bengali learners, especially in the case of teaching pronunciation. Following is the summary of suggestions implicated by these studies:

Both Bengali and English have their distinct phonemic systems and differ considerably in terms of phonemic inventory and their pronunciation. Teachers need to make a detailed contrastive analysis of English and Bengali Phonemics. To facilitate the comparisons, IPA symbols can be used.

Bengali researchers of ESL (e.g., Barman, 2009) have observed that Bengali learners of English are likely to face difficulties in several areas of pronunciation. Since the length of Bengali vowels is not a distinctive feature, Bengali learners tend to pronounce both /i/ and /I :/ as /i/. Again the vowel sounds in words such as 'smart and bird because of substantial problems in learners' articulation and the perception of utterances because the difference between them is not that much exercised in their L1. To solve these problems, teachers need to create study materials with a clear focus on these differences between English and Bengali pronunciation.

Furthermore, the Bengali speaking learners face difficulties in pronouncing and perceiving English diphthongs mainly because of their mother tongue interference. English has 8 diphthongs, each of which is a combination of two monophthongs - one gliding into the other and naturally longer than a pure vowel, whereas Bengali possesses 18 regular diphthongs, which are characteristically different from and shorter than the English ones. As a result, Bengali learners pronounce only the first part of a diphthong and make it identical to a monophthong, e.g., 'late/leit/ is pronounced like 'let'/let/. Teachers need to raise learners' awareness of these issues.

Following the study of Islam (2017), teachers can create an inventory of the consonants in English, which will pose learning difficulties for the Bengali learners of English.

Apart from it, Stockwell, Bowen and Martin's (1965) hierarchy of difficulty in comparing two languages can be followed to investigate how Bengali and English differ in categories such as differentiation, new category / absent category, coalescing, and correspondence. Following this hierarchy, teachers need to focus in their curriculum the areas in which the native language has one form, but the target language has two. Teachers also need to take into consideration the categories that are present in the target language but absent in the native language.

\section{Conclusion}

Although CA has its limitations, its application in finding the possible source of errors in SLA cannot be denied, as is evident by the continuous empirical studies involving $\mathrm{CA}$ in recent years. CA can prove to be relevant in the case of teaching pronunciation in SLA. Moreover, with the recent development in information technology, more studies involving large corpora need to be undertaken to gain empirical evidence of the role of the L1 as a potential source of errors in L2.

\section{References}

Anjarningsih, Harwintha Y., and Anisa Saraayu. "A Phonetic Contrastive Analysis of English Words in Three Japanese Songs by AKB48." Humaniora, vol. 27, no. 3, 2015, pp. 350-361.

Ashour, Hadeel Mohammad. "Major Differences between Arabic and English Pronunciation Systems: A Contrastive Analysis Study." AlLisan International Journal for Linguistic and Literary Studies, vol. 1, no. 1, 2017.

Barman, Binoy. "A Contrastive Analysis of English and Bangla Phonemics." Dhaka University Journal of Linguistics, vol. 2, no. 4, 2009, pp. 19-42.

Dulay, H., and M. Burt. "Creative Construction in Second Language Learning and Teaching." Language Learning, 1976, pp. 65-79.

Duscova, Libuše. "Similarity - An Aid or Hindrance in Foreign Language Learning?" Folia Linguistica, vol. 18, 1984, pp. 103-115.

Fries, Charles C. Teaching and Learning English as a Foreign Language. University of Michigan Press, 1945.

Gass, Susan M., et al. Second Language Acquisition: An Introductory Course. Routledge, 2013.

Islam, A.K.M. Mazharul. "A Comparative Study between English and Bangla Vowel System." 
Bulletin of Advanced English Studies, vol. 1, no. 2, 2018, pp. 130-137.

Islam, Syed Mazharul. "A Contrastive Analysis of English and Bengali Consonants." Journal of Education and Social Sciences, vol. 8, no. 1, 2017, pp. 159-170.

Kissová, Olga. "Contrastive Analysis in Teaching English Pronunciation." Section Language \& Linguistics (AH), vol. 2, 2020, pp. 39-65.

Labov, William. The Social Stratification of English in New York City. Cambridge University Press, 1966.

Lado, Robert. Linguistics Across Cultures. University of Michigan Press, 1957.

Lennon, Paul. "Contrastive Analysis, Error Analysis, Interlanguage." Bielefeld Introduction to Applied Linguistics. Edited by S. Gramley and V. Gramley, Aisthesis-Verlag, 2008, pp. 51-60.

Richards, Jack C. "A Non-Contrastive Approach to Error Analysis.” Error Analysis: Perspectives on Second Language Acquisition. Longman, 1974, pp. 172-188.

Schachter, Jacquelyn. "An Error in Error Analysis." Language Learning, vol. 24, no. 2, 1974, pp. 205-214.

Skinner, Burrhus Frederic. Verbal Behavior. Prentice-Hall, 1957.

Stockwell, Robert P., et al. The Grammatical Structures of English and Spanish. University of Chicago Press, 1965.

Tajareh, Mahboobeh Joze. "An Overview of Contrastive Analysis Hypothesis." Cumhuriyet Üniversitesi Fen Fakültesi, vol. 36, no. 3, 2015.

Weinreich, Uriel. Languages in Contact: Findings and Problems. Linguistic Circle of New York, 1953.

Zobl, Helmut. "The Formal and Developmental Selectivity of L1 Influence on L2 Acquisition." Language Learning, vol. 30, no. 1, 1980, pp. 43-57.

\section{Author Details}

Arjumand Ara, Assistant Professor, University of Asia Pacific, Dhaka, Bangladesh,

EmailID: arjumand@uap-bd.edu. 